\title{
Brief Comment on the Challenge and Opportunities for Effective Containment of the Type 2 Diabetes Mellitus Epidemic that Af- fects the World Population
}

\author{
Maria Eugenia Velasco-Contreras* \\ Division of Family Medicine, Primary Health Care Unit, Mexican Social Security Institute, Mexico
}

* Corresponding author: Maria Eugenia Velasco-Contreras, Specialist in Internal Medicine, Medical Program Coordinator, Coordination of Comprehensive Health Care at the First Level, Division of Family Medicine, Primary Health Care Unit, Address of Medical Benefits, Mexican Social Security Institute Hamburg 18 First Floor, Juárez Colony, CP 6600, Cuauhtemoc Delegation, CDMX, Mexico,E-mail: maria.velasco@imss.gob.mx; mariaeugeniavelasco53@gmail.com

It is a chronic disease associated with multiple health problems: Cardio-cerebrovascular, cancer, behavioral disorders, depression or anxiety, localized or generalized neuropathy problems due to irritation or destruction of the myelin layer, non-traumatic lower limb amputation, blindness, terminal renal damage, the leading cause of death in many countries, excessive expenditures for families and health services that affect society globally and very aggressively to emerging countries [1-4].

No doubt this chronic disease has been studied and clearly described associated with the metabolic syndrome with high stress hormones such as cortisol, adrenaline, abnormal insulin, problems in the production and function of thyroid hormones, hormonal factors of the hypothalamus, growth factors and abnormal reproduction of tissues with cancer development [5-7].

The picture is further complicated by the epidemic of the use of legal drugs, such as tobacco and alcohol, which are accessible and highly available to the poorest populations, as the health damage they cause is clearly associated; smoking to DM2 and abusive alcohol consumption to high blood pressure [8,9].

The work of the organizers of health services, public health teachers, preventive medicine, health educators, community promoters, nutritionists, culinary promoters, services of relaxation techniques, promotion and techniques for physical activity, psychological tools to improve resilience, primary, secondary, baccalaureate, university, writers, radio and television entertainment producers, movies; Politicians and with much emphasis the personal dedicated to the health care in any modality, we must participate so that together we manage to modify the aggressive course of these diseases in the world-wide society [10-13].

But above all let go of the belief that there are excellent drugs and there are no undesirable effects to decrease pressure, glucose, triglycerides, with new developments continuous and very prominent at high prices most of the time inaccessible to those most affected $[14,15]$.

It is recommended to educators in health:

Be very explicit in

1. Why? The consumption of refined sugars, processed foods, hydrogenated vegetable fats, and on the other hand without consumption of vitamins, minerals, fiber and antioxidants present in the great variety of vegetables, grains, fruits, cereals, along the digestive tract, which has a crucial role in the generation of nutritional damage manifested by failure in the quality and quantity of fat cells, muscular, bony cells and in general connective tissue with a participation of macrophages, lymphocytes and leukocytes in general.

2. As emotions such as fear, anger and depression are translated as elevation of the response of stress hormones and these are involved for the generation of 
hypertension, inflammation, cancer, degeneration of vascular walls and capillaries.

3. Understand that people to cope with these emotions resort to relaxation through tobacco and alcohol abuse. And these increase synergy the inflammatory process, degenerative and cancer. It is therefore fundamental the explanation from the youngest of how health is lost by these mechanisms and how can this be jugulated with the daily practice of exercise and with tools of relaxation and psychological care of fear, anger, depression. Instead of dealing with tobacco use and abusive alcohol [16].

4. It is necessary for everyone to know what the body mass index means, why? Some people among their families have such a different response to eating similar foods and encourage everyone to pay fast and excessive attention from overweight, from childhood before being obese, where it becomes infinitely more complex to solve the loss of health physical. It should also be very explicit in what it means to feed-nutrition-endocrine health, in how appetite, satiety, function of the stomach, duodenum, jejunum, ilium, colon, with pancreas, liver, kidney and adipose tissue, are absolutely integrated in the corporal response to food consumption in general [1].

With the participation of all social leaders we are very sure that the study and compression of these health problems will continue and above all, that it is not so difficult to change the accelerated and worrying course of these chronic diseases that have been mistakenly associated with Old age since they are present since adolescence and is undoubtedly due to the deterioration of the consumption of nutrients in foods of very pleasant taste, to Dictive but very harmful for the microbiota of the digestive system and body nutrition.

All this information must be provided every day, every week, to the whole society and the change we want to see is that it be taken into account and mentioned by the presidents of the governments, and the leaders with greater social ascendancy and among those who dedicate ourselves to the epidemiological surveillance of their behaviour to be able to report monthly as the numbers of mortality from all causes are being lowered; As we feel confident that its impact goes beyond simply addressing the epidemic of type 2 diabetes mellitus world wide.

We finally supported in this last recommendation comments on the attention from the government of social problems that affect the health of many "How did Iceland handle such a complete reversal of drug use?"

The way the country has achieved this change has been radical and evidence-based, but it has largely depended on what might be called a reinforced common sense, Writes Emma Young of Mosaic Science. The laws were modified. The purchase of tobacco to children un- der 18 years, and alcohol to those under twenty years of age, was now illegal. A curfew was put in place, prohibiting youth between the ages of 13 and 16 from being out of the house after $10 \mathrm{pm}$ in winter, from midnight during the summer. But the most important reason for the sharp turn around in substance abuse was due to an increase in family time and more emphasis on extracurricular activities. "Parents were encouraged to attend talks about the importance of spending an amount of time with their children instead of, occasionally 'quality time', talking to their children about their lives, the knowledge that their Children were friends, and keeping their children at home at night". Source State funding also increased to support sports and art programs as well as other clubs. In Reykjavik, families are given a leisure card with a value of 35,000 Kroner (US $\$ 3,902$ ), so that each child can use it for recreational activities. Curiously, Young reports that after the changes were made, "The percentage of children 15 and 16 who reported that they often or almost always spent time with their parents during the week doubled - from 23 to 46 Percent - and the percentage who participated in organized sports at least four times a week increased from 24 percent to 42 percent. Meanwhile, the use of cigarettes, alcohol and cannabis use in this age group collapsed". Harvey Milkman, whose research was critical to the development of the Icelandic program, believes that people are on the threshold of abuse, "They used to take the drug because it was their style to deal with [stress]". Children who are "active Confronters" of stress chase euphoria - either by stealing or by stimulant drugs, while sedative drugs like heroin and alcohol are attractive to those who want to numb their anxiety. His idea provoked another: "Why not organize a social movement around maximum natural euphoria states: Around people having altered states through their own brain chemistry - because it seems clear to me that people want to change their consciousness - Without the Harmful Effects of Drugs". Thus, with a \$1.2 million government grant, Milkman and his team developed a program called the Self-Discovery Project in Colorado, United States, which offers a range of different classes for children at risk - music, dance, hip-hop, art, martial arts - which would lead to alterations in brain chemistry to give them a state of natural euphoria whether it was a reduction of anxiety or a Rush. The children also received life skills training to help improve thoughts about themselves and others. After the self-discovery project was established, Milkman was invited to Iceland in 1991 to discuss his work, and later became an advisor to a residential drug treatment center for teens in Tindar, Iceland. "Of the idea of giving children something better to do", he said. In 1999, the nation wide program was established and teens were on their way to finding a natural, healthy binge without the use of drugs. Would this approach work in the United States? Milkman says that everything depends on the resources of each communi- 
ty, since it would be difficult to implement at the federal level. But if we take into account the annual price of drug abuse in this country, how can we not afford to do it? Similarly, Emma Young asks: "In Iceland - the process brought families together and helped children become healthier in all sorts of ways going to decide that these benefits justify the costs".

\section{Conclusion}

With the result of this program I want to emphasize the importance of addressing the DM2 epidemic with a national policy that calls for the participation of society and the public and private sector, which will make it infinitely easier and more efficient.

\section{References}

1. American Diabetes Association (2017) Prevention or Delay Of Type 2 Diabetes. Diabetes Care 40: S44-S47.

2. Harris MI, Klein R, Welborn TA, Knuiman MW (1992) Onset of NIDDM occurs at least 4-7 yr before clinical diagnosis. Diabetes Care 15: 815-819.

3. Kahn SE, Prigeon RL, McCulloch DK, Boyko EJ, Bergman RN, et al. (1993) Quantification of the relationship between insulin sensitivity and beta-cell function in human subjects. Evidence for a hyperbolic function. Diabetes 42: 1663-1672.

4. (1998) Tight blood pressure control and risk of macrovascular and microvascular complications in type 2 diabetes. UKPDS 38. UK Prospective Diabetes Study Group. BMJ 317: 703-713.

5. Gordon C Weir, Susan Bonner-Weir (2004) Five Stages of Evolving Beta-Cell Dysfunction During Progression to Diabetes. Diabetes 53: S16-S21.
6. (2002) Reduction in the incidence of type 2 diabetes with life style intervention or metformin. N Engl J Med 346: 393403.

7. (1998) Cost effectiveness analysis of improved blood pressure control in hypertensive patients with type 2 diabetes. UKPDS 40. UK Prospective Diabetes Study Group. BMJ 317: 720-726.

8. Velasco-Contreras MA (2013) Daños a la salud de trabajadores del IMSS. Rev Med Inst Mex Seguro Soc 51: 12-25.

9. María Eugenia Velasco-Contreras (2014) Does Smoking and Alcohol Abuse Precipitate and Aggravate the Risk of Metabolic Syndrome? J Metabolic Synd 3: 141.

10. (2014) Proyecto de Fortalecimiento de la Atención Integral de Enfermedades Crónicas en Unidades de Medicina Familiar. DPM, IMSS julio de.

11. American Diabetes Association (2017) Lifestyle Management. Diabetes Care 40: S33-S43.

12. (2014) Correct diet and physical activity. Dirección de Prestaciones Médicas IMSS.

13. Remember that to stop smoking the most effective and proven way is to follow 10 golden rules; prevention of alcoholism, do you have problems in drinking? This you should know PhD E.

14. (1998) Effect of intensive blood-glucose control with metformin on complications in overweight patients with type 2 diabetes (UKPDS 34). UK Prospective Diabetes Study (UKPDS) Group. Lancet 352: 854-865.

15. Riddle MC (2003) Editorial: Sulfonylureas Differ in Effects on Ischemic Preconditioning--Is it Time to Retire Glyburide? J Clin Endocrinol Metab 88: 528-530.

16. Raghavendra Rao, MD Tamara Hershey (2012) The Impact of Hypoglycemia on the Developing Brain. Translational Endocrinology \& Metabolism 3: 137-159. 